\title{
Lack of principles
}

The genetic basis of cancer is a cornerstone of modern cancer research that began to unravel over a century ago.

In 1890, David von Hansemann described in detail the mitotic figures of 13 different carcinoma samples. In every case, he found examples of aberrant mitotic figures. These included multipolar mitoses and anaphase figures that showed asymmetric distribution of 'chromatin loops' (or chromosomes). He postulated that these aberrant cell divisions were responsible for the decreased or increased chromatin content found in cancer cells.

At the beginning of the twentieth century, the zoologist Theodor Boveri pursued this - largely ignored - association between aberrant mitoses and malignant tumours. One of his important innovations was to devise experimental manipulations of sea urchin eggs that allowed him to induce multipolar mitoses and, therefore, aberrant chromosome segregation. Boveri, for example, found ways to generate cells with multiple copies of the centrosome - an organelle that organizes the poles of the mitotic spindle, which he had also discovered and named. By following the fate of cells with different chromosomes, he surmised that individual chromosomes were qualitatively dissimilar and transmitted different inheritance factors. He then suggested that aberrant mitoses led to the unequal distribution of chromosomes, which, in most cases, would be detrimental. Yet, on occasion, a "particular, incorrect combination of chromosomes" would generate a malignant cell endowed with the ability of "schrankenloser Vermehrung" (unlimited growth), which would pass the defect on to its progeny. The foundations for viewing cancer as a genetic disease were laid.

Boveri applied his concept to explain disparate phenomena linked to cancer, and made a number of bold and bafflingly accurate predictions. Today, we can see that he foretold the existence of cell-cycle checkpoints ("hemmungseinrichtungen"), tumour-suppressor genes ("teilungshemmende chromosomen") and oncogenes ("teilungsfoerdernde chromosomen"). He further envisaged that 'poisons' (including nicotine), radiation, physical insults, pathogens, chronic inflammation and tissue repair might all be linked to the development of cancer by indirectly promoting aberrant mitoses or other events that cause chromosome imbalances. With astonishing prescience, Boveri applied his model further to explain the emergence of different tumour types within one tissue, and anticipated the clonal origin of tumours, the allelic loss of recessive chromosome elements, the heritability of cancer susceptibilities, the similarity of the steps that initiate tumorigenesis and those responsible for cancer progression, and the sensitivity of cancer cells to radiotherapy. All of these ideas have since found wide acceptance and molecular explanations.

Subsequent work by several investigators showed that known carcinogens, such as ionizing radiation, acted as mutagens, which further underscored the genetic basis of cancer. A consistent chromosomal abnormality that was found in 1960 in chronic myeloid leukaemia - the Philadelphia chromosome (see Milestone 10) - lent further support to this idea.

Closely linked to the Boveri hypothesis is the idea of genomic instability driving the accumu-

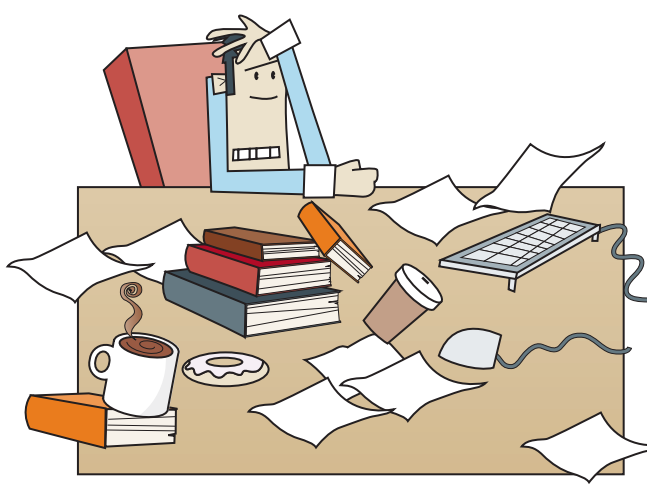

(C)Neil Smith

lation of chromosome aberrations and mutations in cancer cells. Work by Robert Schimke and colleagues showing that cancer cells tend to amplify genes involved in drug resistance, and that these changes can be unstable, was among the first evidence of genomic instability in cancer. Today, the concept has been extended by insights into the mechanisms underlying chromosome imbalances, increased mutation rates and other forms of genetic instabilities, many of which are relevant to the development of human cancer (see Milestone 22).

With the advantage of present-day knowledge, it is tempting to reinterpret the von Hansemann depiction of the "Prinziplosigkeit als Prinzip der Krebszellen" (lack of principle as the principle of cancer cells) as the common occurrence of chromosome abnormalities and genetic instability in cancer.

Barbara Marte, Senior Editor, Nature

\section{References and links}

ORIGINAL RESEARCH PAPERS von Hansemann, D. Ueber asymmetrische Zelltheilung in epithel Krebsen und deren biologische Bedeutung. Virchow's Arch. Path. Anat. 119, 299 (1890) | Boveri, T. Zur Frage der Entstehung Maligner Tumoren (Gustav Fisher, Jena, 1914) | Schimke, R. T., Kaufman, R. J., Alt, F. W. \& Kellems, R. F. Gene amplification and drug resistance in cultured murine cells. Science 202, 1051-1055 (1978)

FURTHER READING Balmain, A. Cancer genetics: from Boveri and Mendel to microarrays. Nature Rev. Cancer 1, 77-82 (2001)

URL

leukaemia

http://www.cancer.gov/cancertopics/types/leukemia 